\title{
Electrochemical Chloride Extraction and Inhibitor Injection in Salt-Contaminated Repair Mortar
}

\author{
Jing Gong ${ }^{1}$, Zhang Shen ${ }^{1}$, Yangyang Tong ${ }^{1}$, Zhipeng Li $^{1}$, Xianming Shi ${ }^{2, *}$ \\ ${ }^{1}$ School of Civil Engineering \& Architecture, Wuhan Polytechnic University, 430023, Wuhan, China \\ ${ }^{2}$ Laboratory of Corrosion Science \& Electrochemical Engineering, Department of Civil and \\ Environmental Engineering, P. O. Box 642910, Washington State University; Pullman, WA 99164- \\ 2910, USA \\ *E-mail: xianming.shi@wsu.edu
}

doi: $10.20964 / 2018.01 .35$

Received: 27 August 2017 / Accepted: 15 October 2017 / Online Published: 1 December 2017

\begin{abstract}
Repair mortar is commonly used to rehabilitate reinforced concrete structures or components that exhibit a relatively high level of distresses. Yet, the repair mortar can be contaminated by salt from its service environment. This work employs a two-dimensional finite element model to investigate the non-stationary transport behavior of ionic species in salt-contaminated and water-saturated repair mortar under an externally applied electric field. The model was experimentally validated and then utilized to evaluate the effectiveness of electrochemical chloride extraction (ECE) with or without electrical injection of corrosion inhibitor (EICI). In the case study, both the ECE alone and the simultaneous ECE+EICI treatment was found effective in decontaminating the zone in front of the steel rebar. In both techniques, the magnitude of current density had a significant effect on removing chloride out of the mortar and increasing the $\mathrm{pH}$ of the pore solution near the rebar, whereas the treatment time did not have a significant effect under some scenarios. The injection of the organic corrosion inhibitor significantly slowed down the removal of chloride. Changes in the ionic distribution in the mortar were generally beneficial in reducing the corrosion risk of the steel rebar and thus extending the service life of the repair mortar.
\end{abstract}

Keywords: Finite Element Modeling; electrochemical chloride extraction (ECE); electrical injection of corrosion inhibitor (EICI); Rebar Corrosion; Repair Mortar

\section{FULL TEXT}

(C) 2018 The Authors. Published by ESG (www.electrochemsci.org). This article is an open access article distributed under the terms and conditions of the Creative Commons Attribution license (http://creativecommons.org/licenses/by/4.0/). 